\title{
O REAL E A POESIA \\ NOS ENTREMEIOS LITORÂNEOS DE PÊCHEUX E \\ LACAN $^{1}$
}

\author{
THE REAL AND POETRY \\ MIXED IN WITH COASTAL OF PÊCHEUX AND LACAN
}

\author{
Lucília Maria Abrahão e Sousa \\ Universidade de São Paulo, USP, Ribeirão Preto, Brasil
}

\begin{abstract}
Resumo: O presente artigo articula o pensamento de Pêcheux e de Lacan em relação ao conceito de real como condição da língua e do inconsciente. Intenta também apresentar a poesia como uma resposta possível ao tratamento do inominável e impossível, sinalizando como dois campos diferentes podem dialogar a partir de seus dispositivos específicos. A título de ilustraçâo, analisamos alguns trabalhos de Zack Magiezi reunidos no livro Estranherismo; sabemos que o autor lançou seus posts poéticos nas redes sociais e os publicou no Instagram e Facebook, o que fez a sua obra e seu nome circularem de modo intenso nos últimos anos.
\end{abstract}

Palavras-Chave: Pêcheux; Lacan; língua; inconsciente; real.

Abstract: This article articulates the thought of Pêcheux and Lacan against the real concept as a condition of language and the unconscious. It also intends to present poetry as a possible response to treatment of the unnameable and impossible, signaling as two different fields can be dialogue from your specific devices. By way of illustration, we analyze some Zack Magiezi works collected in the book Estranherismo ; we know that the author has released his poetic posts on social networks and published them on Instagram and Facebook, which made his work and his name circulated intensely in recent years.

Key-words: Pêcheux; Lacan; language; unconscious; real.

\section{De real e poesia: a estranha tessitura do sujeito na língua}

"Sinto que sou pequeno demais para mim mesmo. Alguém teima em escapar de mim" (MAIAKOVSKI, 2006, p.14).

Teorizar o real e a poesia implica lidar com a angústia da folha em branco, táo transbordante de presenças e de desejo, para no-depois constatar certa ordem de ausências que se corporificou com as palavras, com o que não pôde ser dito nem estar ali e com o que restou fora no de-dentro elaborado.

\footnotetext{
${ }^{1}$ Parte deste escrito foi publicado na Revista Stylete Lacaniano, n. 5, 2016.
} 
Esse jogo tenso e pendulante entre dizer e apagar no dito, entre presença e falta, entre tentativa de preenchimento e vazio, aponta um trabalho nas fronteiras e bordas, táo caro ao linguista e ao (psi)analista.

Tomar o tema das ressonâncias da Psicanálise no campo da Análise do Discurso - especialmente no tocante à definição de real - implica considerar que, nos dois campos em jogo, a cartografia das trilhas tem uma ordem de dentro-e-fora textecido, esquecido e marcado por diferenças e entremeios litorâneos. Farei aqui um percurso modesto: fazer dialogar as noçóes de real e poesia em quatro seminários de Lacan (1959-1960; 1962; 1964; 19761977), e na obra de Pêcheux (1983) e Gadet e Pêcheux (1966-1983) para mobilizar, tanto quanto possível, o modo como ambos lidaram e assinalaram, em dispositivos bastante distintos, os limites da própria palavra. Mais ainda, tal movimento faz considerar que esses dois campos, muito diferentes entre si, tocam a língua no que ela tem de presença e de ausência, e também no que ela suporta de impossível dizer como constitutivo de todo dizer.

Lacan, ao longo do Seminário - Livro 7 , define o sujeito fal( $\mathrm{t}$ ) ante a partir do "que existe de aberto, de faltoso, de hiante, no centro do nosso desejo" (LACAN, [1959-1960] 2008, p. 104) e a partir do que não se completa, tampouco se fecha, mas configura-se com idas e vindas do significante, em voltas e novos turnos de procura do objeto que é/está perdido para sempre. Objeto que:

\footnotetext{
[...] nấo pode ser reencontrado. É por sua natureza que o objeto é perdido como tal e jamais será reencontrado. Alguma coisa está aí esperando algo melhor, ou esperando algo pior, mas esperando. [...] é esse objeto, Das Ding, enquanto o Outro absoluto do sujeito, que se trata de reencontrar. Reencontramo-lo no máximo como saudade (LACAN, [1959-1960] 2008, p. 68).
}

Aquilo que Freud (1895-1977) designou como constante no aparelho psíquico, em Lacan é definido como aquilo que não cede, não adormece nem se tampona, apenas lança o sujeito em movimentos de "encontrar o que se repete, o que retorna e nos garante retornar sempre ao mesmo lugar" (LACAN, [1959-1960] 2008, p. 94). Irrealizado, intransponível, perdido, trata-se justamente de fenda, hiância, fissura e rasgo inscritos pela perda do corpo da mãe e pela interdiçáo do incesto. Isso engendra uma falta estrutural que se rende à pobreza de toda a palavra, o que Berta (2015, p. 177) denomina de "masoquismo primordial". 
são os signos da Coisa, do impossível do encontro, do mau encontro. Esse é o masoquismo primordial: o encontro faltoso, o encontro de uma fenda impossível de suturar (BERTA, 2015, p. 177).

Esse é o ponto que me interessa: o mau encontro não tem palavra em seu núcleo, visto que a língua náo dá conta de abrigar e conter essa Coisa, apenas contorná-la; assim, o verbo falta impedido de dar conta do buraco que náo consegue tamponar, tendo somente o percurso de dar mais uma volta a mais - e mais outra e sempre alguma a mais - em torno dele. Ao longo do Seminário - Livro 11, Lacan avança na direção de anotar "algo que é da ordem do não-realizado" (LACAN, [1964] 1973, p. 28), cuja materialidade se dá a ver em "tropeço, desfalecimento, rachadura [...] dimensão de perda” (LACAN, [1964] 1973, p. 30). Perda sinalizadora de Das Ding, pois "a ruptura, a fenda, o traço da abertura faz surgir ausência - como o grito náo se perfila sobre fundo de silêncio, mas, ao contrário, o faz surgir como silêncio" (LACAN, [1964] 1973, p. 31). É interessante marcar que esse silêncio não é impedimento, mas impossível de dizer, já que a palavra não entra, náo cabe, não comparece nesse núcleo duro que ela náo consegue tocar. Assim, a língua tem a tarefa de fazer instalar o vazio, materializar o furo, manifestar o buraco oco do humano. Assim, dizendo, repetindo e tropeçando, o sujeito segue seus trilhamentos entre significantes, emergindo entre eles.

Nessas redes de associaçôes significantes, algo se inscreve sempre incompleto, manco, roto e capenga na voz do sujeito, instalando justamente nela o impossível. Dito de outro modo, é pela palavra que se dá a ver o sem palavra, o impossível palavrar, o real. No Seminário denominado Angústia, Lacan ([1962-1963] 2005, p. 90) indica a "funçâo essencialmente precária de condenar o real a tropeçar eternamente no impossível. Não temos outro meio de apreendê-lo senáo avançando de tropeço em tropeço." Ou seja, a cada tentativa de nomear, o inominável comparece como centro em torno do qual todos os movimentos simbólicos orbitam, em torno do qual o sujeito faz giros de desejar. E faz poesia. Vejamos.

$\mathrm{Na}$ década de 70, Lacan encontra-se às voltas com a poesia chinesa e a potência do som e da homofonia como uma instância do poético. Ao longo do Seminário $24^{2}$, ele aproxima a função do analista à escuta disso que, na língua, é efeito de um reviramento, "uma ambiguidade, um duplo sentido" em torno do furo constitutivo do humano e do furo na ordem da própria significação.

\footnotetext{
${ }^{2}$ Ainda inédito.
} 
[...] A poesia se funda precisamente sobre esta ambiguidade de que falo e que qualifico de duplo sentido. Se com efeito a língua - é aí que Saussure tem seu ponto de partida - é fruto de uma maturação, de uma madurez que se cristaliza com o uso, a poesia resulta de uma violência feita a este uso [...] (LACAN, [1976-1977], s.p.). ${ }^{3}$

Assim, Lacan aponta um outro modo de tratamento do real, já que essa "violência poética" é o que assenta uma espécie de furo nos sentidos estabilizados, melhor trabalho que uma análise pode levar a termo. Afirma ele que "a astúcia do homem é enfrentar tudo isto, eu lhes disse, com a poesia, que é efeito de sentido, mas, também de furo" (LACAN, [19761977], s.p. $)^{4}$. Assim, o trabalho do analista é sustentado pela poesia, já que uma interpretaçáo só pode ser inferida a partir dela, dos barulhos de puro som de nada da poesia, dos equívocos e tropeços em que elisóes produzem significantes esvaziados de qualquer sentido, das torçóes de sentido em que o nonsense e a surpresa fazem sua morada. Ao analista cabe escutar tais ruídos no manejo de "cortar o enunciado que imita o poético, para que um encontro do significante com real possa criar a oportunidade do sujeito se deparar com algo que não atenda ao formalismo da consciência" (ANDRADE, 2015, p. 2).

Não atender ao "formalismo da consciência" implica ter coragem para tatear algo próximo ao inominável e ao real, espiralando em torno dele um contorno de possibilidades com a língua, esse pouco com o qual trabalhamos, quiçá, um contorno de poeturas com os sentidos que sempre podem ser outros. De certo modo, Pêcheux também se encontra com tal tarefa e, de maneira outra com outro dispositivo teórico, toca a noção de real. Sobre isso, Plon (2005, p. 41- 42) afirma:

Tudo parece ter se passado como se Michel Pêcheux tivesse entendido bem alguma coisa de essencial procedente da psicanálise lacaniana, mas como se, ao mesmo tempo, ele não chegasse a se livrar do peso ou da armadura, cujas exigências mínimas eram da ordem da prudência, uma prudência comandada pela política; como se ele não pudesse se autorizar totalmente, dar-se o direito de aceitar não somente que isso falha mas que isso deve falhar, que é inelutável que isso falhe, que isso falhará para sempre e que é vão esperar, ou mesmo tentar apressar [...] a chegada do momento, do tempo em que isso não falhará mais, do tempo das manhãs radiosas em que isso não caminhará mais obliquamente, em que isso funcionará sem equívocos, sem defeitos, sem furos [...].

\footnotetext{
${ }^{3}$ Disponível em: http://coloquioarteepsicanalise.blogspot.com.br/2013/01/a-poesia-em-lacan. html. Acesso em: 30 jun. 2016.

${ }^{4}$ Disponível em: http://coloquioarteepsicanalise.blogspot.com.br/2013/01/a-poesia-em-lacan. html. Acesso em: 30 jun. 2016.
} 
Em duas obras pechetianas, o real comparece: em A Língua Inatingível - o discurso na história da linguística, dele em coautoria com Gadet (1966-1983), e em sua obra solo Discurso - estrutura ou acontecimento (1983). Vejamos o que nos diz na primeira. Dedicam-se os autores, com especial brilhantismo, a formular a força do witz, joke, do equívoco, da língua e seu inatingível, do traço sempre inalcançável e ausente da palavra, e da poesia como resposta possível na busca ao sem-fim de uma palavra que terminasse por encerrar e completar o sentido.

\begin{abstract}
A linguística, ciência da língua e das línguas, ciência da divisão sob a unidade, traria assim, inscrito em seu destino o desejo irrealizável de curar a ferida narcísica aberta pelo conhecimento da divisão. Seria esse destino que induz a estranha propensão da linguística a se resvalar na ignorância? Essa surdez interna ganha terreno cada vez que a linguística deixa o real da língua, seu objeto próprio [...] (GADET; PÊCHEUX, 1966-1983, p. 19).
\end{abstract}

Nesse recorte, os autores não apenas flertam com a Psicanálise de Freud e Lacan, ao referenciar a noção de "ferida narcísica", mas, principalmente, apresentam-se no lugar de defesa de um real que a própria Linguística teria escamoteado em seu interior e em seu campo, real este que definem como real da língua. $\mathrm{Na}$ esteira dos estudos sobre a teoria do valor em Saussure e sobre os anagramas, sinalizam que há "o retorno de um ponto recalcado da linguística...” (GADET; PÊCHEUX, 1966-1983, p. 22), o real, que pode ser definido como a ordem de "um impossível, inscrito na própria ordem da língua” (GADET; PÊCHEUX, 1966-1983, p. 32). Nesses momentos de formulação sobre o real, os autores sustentam-se no trabalho $\mathbf{O}$ amor da língua, de Milner (1987): "O 'real da língua' é, portanto, o impossível que lhe é próprio” (MILNER, 1987, p. 52). Dito de outro modo, o que a língua mantém de inatingível, impossível, indizível em si mesma, em seu interior é o seu traço mais genuíno de língua. Por conta disso, a Linguística teria que considerar não apenas o que manca no funcionamento do sistema, mas, sobretudo, o que lhe é puro limite de nunca conseguir esgotar toda a possibilidade da palavra.

Pêcheux traz um "real em vários sentidos", como algo que aborde um "outro tipo de saber", para além das "coisas-a-saber", um saber, que de acordo com ele nâo pode ser transmitido, aprendido e ensinado, mas que ainda assim, continua produzindo efeitos. O real já se coloca de saída para o sujeito, é anterior a ele e o invade, produz efeitos. [...] Pêcheux nos diz que não descobrimos o real, mas que nos deparamos com ele, deste modo, o real da história nos coloca diante disto: de que há uma impossibilidade de acordo simbólico, posto que há um desacordo social que representa um buraco na sociedade (CARNEVALE, 2012, p. 44-45). 
Tal "novidade insuportável" assim dita por Gadet e Pêcheux (19661983), estabelecida pelos estudos anagramáticos de Saussure, institui "uma relação com o real de alíngua" (GADET; PÊCHEUX, 1966-1983, p. 59), ou seja, coloca a língua em relação com aquilo de que ela é feita, seu indizível, sua esfera de palavra sem corpo de palavra, seu puro som de nada. Nos termos de Milner (1987, p. 19):

\begin{abstract}
Abandonemos um instante a evidencia da linguagem da mestria para nos determos no que é mínimo: falar de língua e de partição é colocar que tudo não se pode dizer. Em outros termos, o puro conceito de língua é aquele de um não-todo marcando a alíngua; ou a língua é o que suporta a alíngua enquanto ela é não-toda. [...] Mas a leitura não pode parar aí: do que a verdade não se diga toda, pode-se também concluir que a verdade não é nada mais de que aquilo em relação ao que as palavras faltam; ora, as palavras sempre faltam, e o náo-todo que marca a verdade enquanto que ela deve ser dita, marca também alíngua, enquanto todo dizer verdadeiro passa por ela. Donde se conclui que, como a própria verdade, a alíngua atinge o real. [...] a língua suporta o real da alíngua.
\end{abstract}

Nessa direção, alíngua está para o impossível do mesmo modo como o sujeito está para o objeto perdido: disso o que se ouve são apenas (e)feitos de dizer, muitos dos quais tão somente ruídos, retalhos, pedaços que não podem ser explicados nem emendados. Nisso - da língua desfiada sob si mesma e incompleta e incapaz de tamponar o furo - opera um certo modo de fazer o náo-todo ser manifesto, a homofonia acesa e o sentido mutilado. Com essa matéria é feita a poesia e, nesses termos, de real.

O surpreendente é que o fracasso não seja absoluto e que um poeta se reconheça nisto que ele consiga efetivamente, senão preencher a falta, ao menos afetá-la. Na alíngua, que ele trabalha, acontece que um sujeito imprima uma marca e abra uma via onde se escreve um impossível a escrever (MILNER, 1987, p. 26).

E eu acrescento: uma teoria que se abre a via de um impossível que não se escreve de todo, apenas deixa rastros pelos seus efeitos, seus resíduos e suas ressonâncias. Impossível este que toma Pêcheux de assalto (1983, p. 29), em outra obra, da seguinte maneira: “'há real', isto é, pontos de impossível, determinando aquilo que não pode não ser 'assim' (O real é o impossível... que seja de outro modo). Náo descobrimos, pois, o real: a gente se depara com ele, dá de encontro com ele, o encontra”. Dá de encontro ao modo de um trombamento, um acidente inesperado com ele, sempre. Aqui é possível nuançar um modo de Lacan e Pêcheux se encontrarem (e vice-versa), pois 
ambos dão notícia do impossível nas suas teorizaçóes e na forma de definir o real como tropeço. E um tropeço no campo das disciplinas de interpretaçáo, aquelas tão domesticadas pela ordem do estabilizado e categorizável. Sobre isso, Pêcheux (p. 43) faz ranger a opacidade.

\begin{abstract}
Interrogar-se sobre a existência de um real próprio às disciplinas de interpretação exige que o não-logicamente-estável não seja considerado a priori como um defeito, um simples furo no real [...] Logo: um real constitutivamente estranho à univocidade lógica, e um saber que não se transmite, não se aprende, não se ensina, e que, no entanto, existe produzindo efeitos.
\end{abstract}

Abrir fendas nas noçóes de unidade, completude e transparência atribuídas à língua e ao seu funcionamento não é tarefa fácil hoje, no tempo de Pêcheux, talvez mais difícil ainda; isso porque significa escrever uma teoria sempre provisória, que coloca em jogo a ordem do discurso dada apenas pelos efeitos de/em movimentos imprevisíveis de sentidos dis-postos a partir da posição que o sujeito ocupa na sua singular relação com a ideologia e o desejo. Nessa visada, temos a urgência de tomar a língua em sua plástica equivocidade, marcada pela falta e pelo impossível que lhe são constitutivos, o que significa inferir tomá-la em sua condição de poesia. Citando Milner, Pêcheux (1983, p. 51) formula que "nada da poesia é estranho à língua. Nenhuma língua pode ser pensada completamente, se aí não se integra a possibilidade da poesia".

Nesses termos, ao linguista e ao analista cabe se haver com a poesia da língua e escutar os rumores delas em deslocamento, e isso tentaremos empreender a seguir.

\title{
O inesperado efeito poético sobre ela, em notas e diálogos
}

"Pois se as estrelas brilham, é porque alguém precisa disto!" (MAIAKOVSKI, 2006, p. 23).

O poeta Zack Magiezi lançou seus posts poéticos nas redes sociais e publicou no Instagram e no Facebook, o que fez a sua obra e seu nome circularem de modo intenso nos últimos anos. Reuniu parte de seus trabalhos e publicou o livro Estranherismo (2016), empreendendo logo de saída a tarefa de definir o título de sua obra: "1 causar estranhamento. 2 o que é de dentro e não conhecemos. 3 aventurar-se com emoçóes desconhecidas. 4 surpreender a si mesmo. 5 estranhar com o objetivo de ampliar os limites" (MAGIEZI, 2016, s.p.). Tomamos o trabalho dele por 
considerar que, de algum modo, toca o que percorremos teoricamente até aqui: estranhamento, desconhecimento, surpresa e ampliaçáo são efeitos do que o poético produz na ordem da língua e dos modos de o sujeito ser afetado por ambos. Recortamos, dentro do livro, as páginas cor de rosa, nas quais o autor organiza as "Notas sobre ela".

Vale marcar aqui a polissemia para o termo "notas", o que seriam elas diante dela. Notas de uma sinfonia, de uma disciplina, de um vinho, de um saber, de dinheiro, de escritos... Para fazer versos sobre ela, o significante "notas" imprecisa e esburaca o efeito de fechamento dos sentidos, abrindo as pétalas dos (im)possíveis para vários campos semânticos. Ela, seria uma ou seriam várias? Como percorrer os caminhos sobre ela se o que se tem em jogo é um dizer sobre, um olhar estranho (cheio de "estranherismo"...) de poeta sobre uma mulher, o dele dizendo dela. Isso posto, sinaliza que estamos na trilha da escuta da equivocidade da língua, da plasticidade dos efeitos e do amor (à língua e ao saber inconsciente). Entremos no primeiro poema.

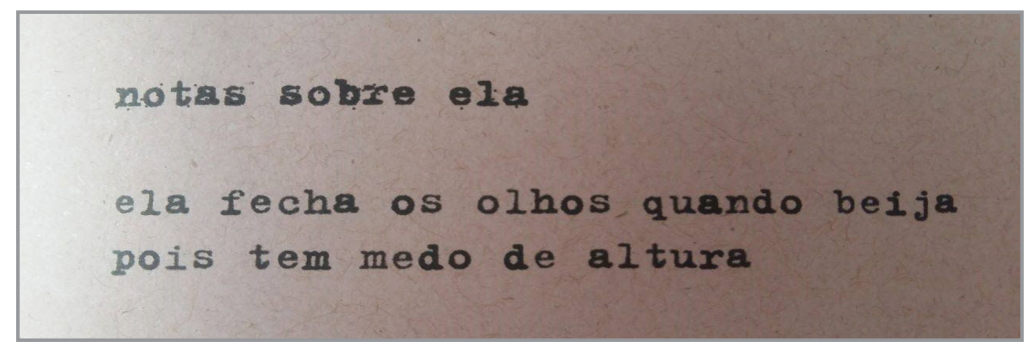

Fonte: MAGIEZI, 2016, p. 83.

No sentido estrito, medo de altura diz respeito a lugares e ou espaços físicos que coloquem o corpo longe do cháo, e o ato de fechar os olhos tem seu uso mais frequente para evitar vertigem. Ela, no entanto, surpreende, pois o faz quando beija. Esse lugar inesperado, de colocar em relaçáo e em causa o beijar com o medo de altura, inscreve a propriedade do poético de fazer furo na significação previsível e de produzir um buraco na ordem da língua que o leitor precisa suturar a sua moda. 
notas sobre ela

ela é uma bailaxina

que aprendeu a dançar conforme o caos

Fonte: MAGIEZI, 2016, p. 146.

Ora, é do senso comum que toda bailarina dança e aprende a dançar conforme a música. Dança e música são entremeadas como práticas indissociáveis, o que produz um efeito regularizado pela repetiçáo e pelo sentido dominante, digamos assim. Dançar de acordo com o caos é o que fissura esse campo estabilizado, faz abalo no que se espera de uma bailarina, de um aprendizado de bailarina e de sua dança. No entanto, ela aprendeu isso, o diferente, o outro do equívoco, o deslocante do sentido por vir, e essa é a sua poetura.

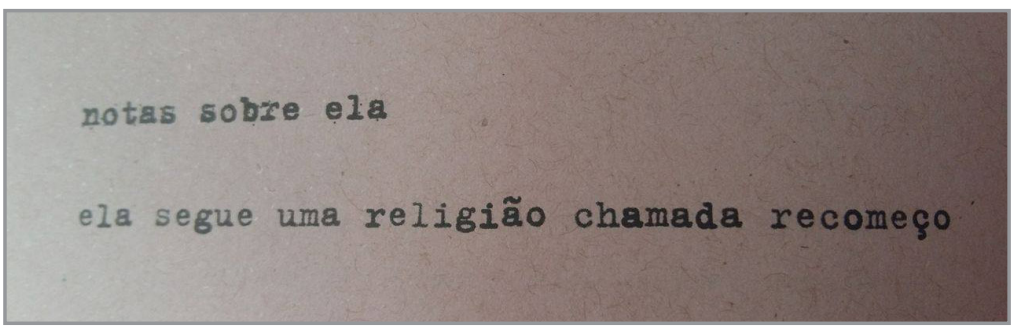

Fonte: MAGIEZI, 2016, p.126.

Em lugar de um nome de religião, o "recomeço", outro furo no esperado que abre espaço para a emergência do poético. Seguir algo implica certa regularidade nos efeitos de concordância e de obediência em relação a uma autoridade, de aceitaçáo de alguma verdade a ser proclamada e repetida, de submissão a um centro que guia e dirige as escolhas do sujeito. Ela faz tropeçar tais efeitos. Sua religião implica um substantivo que faz falar a queda de terminar e começar, de encerrar e recomeçar, de concluir e abrir outro processo. $\mathrm{O}$ poético reside nisso que faz troça do estabilizado, produzindo um reviramento da língua sobre si mesma ao modo de um origami em que uma dobra a mais e outra figura aparece. 
Outra série de poemas do mesmo autor chama-se Diálogo; sempre duas vozes com curtas trocas de turnos em que é possível reconhecer o poético $\mathrm{e}(\mathrm{m})$ seus efeitos.

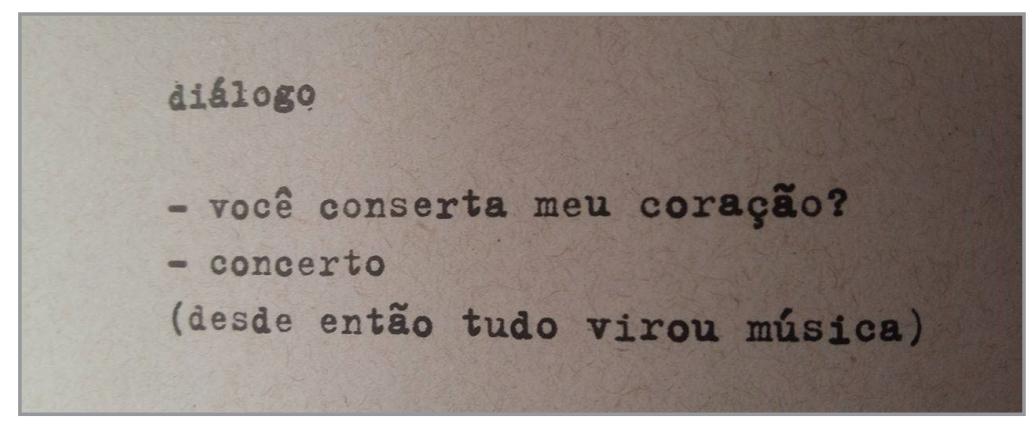

Fonte: MAGIEZI, 2016, p. 66.

Náo se sabe ao certo quem pergunta e quem responde, o que pouco importa. O diálogo de amor comporta qualquer voz como início. O que se demanda aqui é um conserto de coraçáo, o que instala de imediato a decepção amorosa ou a frustração dada por algum desencontro. Perguntase: como consertar um coração? Que tipo de ferramenta poderia ter aí uma empreitada bem sucedida? A resposta rompe com essa antecipação de sentidos esperados e coloca em jogo um significante de ruptura: "conserto", o que cria uma resposta totalmente equivocada e poética para a pergunta, fazendo um reboliço, instalando a desordem, revirando o efeito sempre derrisório e jocoso da língua. Então se fez a música como conserto ao coração sofrido e machucado, desconcertado.

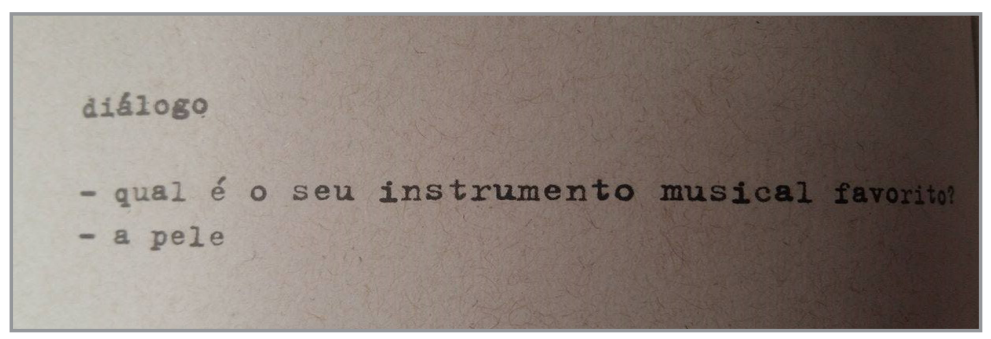

Fonte: MAGIEZI, 2016, p. 40. 
O diálogo acima implica o poético como essa instância do inesperado equívoco e como efeito de uma resposta desejosa ao real e ao tropeço. Ao indagar sobre instrumento musical, espera-se qualquer um, menos a pele, o que joga a resposta em um lugar imprevisível que faz retroagir sobre a pergunta, reconfigurando-a. E não é que a pele também produz seus sons? Tocar um instrumento passa a ter equivalência com tocar a pele, arrancando dela notas e melodias ao modo de uma música.

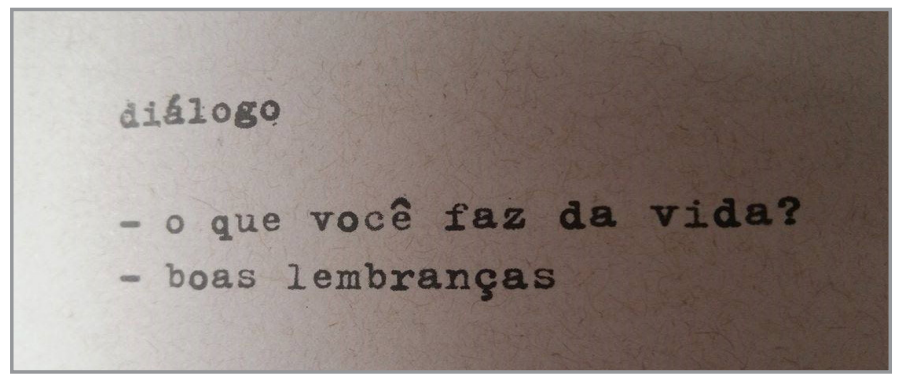

Fonte: MAGIEZI, 2016, p.182.

A frase que costumeiramente está atrelada a uma pergunta sobre trabalho, sobre afazeres do cotidiano ligados ao ganho financeiro ou profissional, recebe uma resposta outra, marcando uma tarefa pouco provável para o que inscreve no sócio-histórico como efeito de urgência no tocante à sobrevivência, carreira, sucesso material. A resposta é poética por torcer os sentidos ligados ao mundo material, colocando em jogo outros advindos da memória, das lembranças e da saudade. Fazer-se aí algo de trabalho é o giro que se dá em torno do mesmo, fazendo emergir o outro. Assim, o poético em jogo, a palavra com seus poros abertos, o fosso aberto no sentido único, o buraco e a borda tracejados de humor, de joke, de chiste, de troça e de leveza a nos indicar que a língua serve à poesia e faz dela sua condiçáo.

\section{Conclusáo}

É preciso arrancar alegria ao futuro (MAIAKOVSKI, 2006, p.41).

Esse breve exercício de colocar a voz de Lacan (e Freud) e de Pêcheux (e Saussure) em relação não deseja o risco de tomar a importação de 
conceitos como automática, o que seria uma janela estreita para pensar os dois campos do saber, a psicanálise e o discurso. No entanto, o trabalho de escutar ressonâncias de um autor em outro faz falar os bons frutos colhidos nos atalhos a partir do que cada um depositou de si na forma de pensar linguagem, sujeito e o poético. E também indicia como tais autores, cada um em seu dispositivo, deu a sua resposta ao real, ao tropeço e ao horror do inominável, perpassando algo do poético seja no ato da interpretação (psi) analítica, seja no gesto da análise dos discursos. No fundo, os quatro nomes citados antriormente nos dáo pistas de efeitos do real, efeitos do impossível que tanto os causou (e nos causa) a girar, efeitos da alíngua que "excede a língua e imprime nela a marca pela qual se faz conhecer" como ensina Milner, e por fim - por que não dizer efeitos de amor à língua e ao saber inconsciente? - efeitos da poesia nossa de cada dia.

\section{Referências}

ANDRADE, C. Escrita poética chinesa e a interpretaçáo no último Lacan. Opção Lacaniana on line nova série, ano 6, n. 18. 2015.

BERTA, S. L. Escrever o trauma, de Freud a Lacan. São Paulo: Annablume. 2015.

CARNEVALE, A. M. Queridos... Espero que esta voz encontre todos bem de saúde - o silêncio e o real na constituiçáo do sujeito. Tese (Doutorado). Programa de Pós-Graduação em Letras, UFF, 2012.

FREUD. Projeto para uma psicologia científica. Rio: Imago, [1895] 1977.

GADET, F.; PÊCHEUX, M. A língua inatingível - o discurso na História da Linguística. Campinas: Pontes, [1966 - 1983] 2004.

GARCIA-ROSA, L. A. O mal radical em Freud. Rio de Janeiro: Jorge Zahar Editor, 1990.

LACAN, J. "L'insu que sait de l'une-bévue s'aile à mourre". Seminário inédito, [1976-1977].

Seminário, Livro 7 - A ética da psicanálise. Texto estabelecido por Jacques-Alain Miller. Tradução Antônio Quinet. Rio de Janeiro, Jorge Zahar Editor, [1959 - 1960] 2008. 
Seminário, Livro 10 - A angústia. Tradução M. D. Magno. Rio de Janeiro: Jorge Zahar Editor, [1962-1963] 2005.

Seminário, Livro 11 - Os quatro conceitos fundamentais da psicanálise. Tradução M. D. Magno. Rio de Janeiro, Jorge Zahar Editor, [1964] 1973.

MAGIEZI, Z. Estranherismo. Rio de Janeiro: Bertrand Brasil, 2016.

MAIAKOVSKI, W. A geração que esbanjou seus poetas. In: Jakobson, R. A geraçáo que esbanjou seus poetas. São Paulo: Cosac Naif, 2006.

MILNER, C. O amor da língua. Porto Alegre: Artes Médicas. 1987.

PÊCHEUX, M. O discurso - estrutura ou acontecimento. Campinas, Pontes, [1983] 1997.

Lucília Maria Abrahão Sousa O real e a poesia Nos entremeios litorâneos de Pêcheux e Lacan Submetido em: 2016-04-24

Aprovado em: 2016-06-29 